\title{
Effects of Nutrient Density and exogenous enzymesin Starter Diet on Performance, Intestinal Microflora, Gut Morphology and Immune Response of Broiler Chickens
}

\section{-Author(s)}

\section{Nabizadeh $A^{\prime}$ \\ Golian A" \\ Hassanabadi All \\ Zerehdaran SIV}

Department of Animal Science, Ferdowsi University of Mashhad - International Campus, PO Box 9176764955, Mashhad, Iran.

" The Excellence Centre for Animal Science, Department of Animal Science, Ferdowsi University of Mashhad, PO Box 91775 1163, Mashhad, Iran.

III The Excellence Centre for Animal Science, Department of Animal Science, Ferdowsi University of Mashhad, PO Box 917751163, Mashhad, Iran.

Iv The Excellence Centre for Animal Science, Department of Animal Science, Ferdowsi University of Mashhad, PO Box 917751163, Mashhad, Iran.

\section{Mail Address}

Corresponding author e-mail address Abolghasem Golian

The Excellence Centre for Animal Science, Department of Animal Science, Ferdowsi University of Mashhad, PO Box 917751163, Mashhad, Iran.

Tel: $\quad$ +989153522058

Email: golian-a@um.ac.ir

\section{-Keywords}

Amino acid density, intestinal morphology, microbiota, growth performance.

\section{ABSTRACT}

A total of 810 one-day-old, straight-run broilers were used to evaluate the effects of dietary nutrient density and feed additives included in the starter diet on their performance, intestinal microbiota, gut morphology, and immune response. A $3 \times 3$ factorial arrangement with three nutrient densities $(100,103.75$ and $107.5 \%$, as recommended) and three feed additives (no additives, $0.5 \mathrm{~g} / \mathrm{kg}$ diet Maxi-Gen, and Maxi-Gen + Superzyme + Bio-Phytase at the rate of 0.5, 0.25 and 0.1 $\mathrm{g} / \mathrm{kg}$ diet, respectively), fed from 1 to $10 \mathrm{~d}$ of age. Similar commercial corn-soy grower and finisher diets fed to all birds from 10-24 and 24$42 \mathrm{~d}$ of age, respectively. There was higher $(p<0.05)$ body weight gain and lower $(p<0.05)$ feed conversion ratio in chicks fed starter diet with $107.5 \%$ nutrient density and Maxi-Gen with or without exogenous enzymes compared with those fed control diet at 10 and $42 \mathrm{~d}$ of age. Lactobacilli and Bifidobacteria counts in the cecal content were increased linearly as dietary nutrient density increased in 10-d-old birds $(p<0.05)$. Higher duodenal and jejunal villus height and villus height to crypt depth ratio $(p<0.05)$ were measured in the birds fed the starter diets with $103.75 \%$ and $107.5 \%$ nutrient density at 5 and $10 \mathrm{~d}$ of age. Total anti-SRBC and IgM titers were significantly higher in the broilers fed the $107.5 \%$ nutrient density diet containing feed additives at 35 day of age. It is concluded that higher nutrient density and the inclusion of feed additives in the starter diet may improve the growth performance, gut morphology, and immune response of broiler chickens.

\section{INTRODUCTION}

The same dietary nutrient specifications for starter Ross 308 broilers were established in 2014 and 2015. However, nutrient requirements may be higher to promote a good start due to the high growth capacity of broilers during this period. On the other hand, their feed intake is relatively low (Kidd et al., 2004), and pancreatic and biliary secretions, required especially for protein and fat digestion, may be insufficient in the first week of post hatch (Noy \& Sklan, 1997). Therefore, higher nutrient bioavailability or densities may be needed due to lack of gut development in this period. Otherwise, feed presents lower digestibility, resulting in a high proportion of undigested in the excreta (Noy \& Uni, 2010). Adedokun et al. (2007) reported that endogenous ileal amino acid flow was approximately $50 \%$ higher on 5 -d-old chicks compared with 21-d-old broiler chicks. Higher densities of critical nutrients and the inclusion of exogenous enzymes have been driven by the idea that nutrient requirements for maximum growth rate may be higher than the current recommendations, as well as that newly-hatched chicks may present poor dietary nutrient utilization due to their undeveloped digestive tract and insufficient digestive enzyme secretion. 
Protein, amino acids, calcium, and phosphorus are considered as critical nutrients to maximize growth performance during the starter period (Swennen et al., 2010). In particular, increasing amino acid density in pre-starter diets increases weight gain at $7 \mathrm{~d}$ of age, and subsequently, due to positive correlation between early live weight and final body weight (Willemsen et al., 2008), they may improve the economic efficiency in broiler chickens (Sklan \& Noy, 2003). It is reported that broiler fed a starter diet with high nutrient density grow faster throughout the entire rearing period (Zhai et al., 2013). There is evidence that some nutrient requirements of broilers, particularly of digestible amino acids in the first $10 \mathrm{~d}$ post hatch may be higher than the current commercial recommendations (Barekatain \& Swick, 2016). Hence, determining dietary amino acid digestibility and density in the starter diet are crucial factors to maximize chick's growth performance.

In addition, soy products and cereal grains may contain several many antinutritional components, which form low or indigestible compounds (Bach Knudsen, 1997). The use of exogenous enzymes is an effective way to reduce the antinutritional component levels in feedstuffs, and therefore, to improve broiler performance (Cowieson, 2005), overall nutrient availability (Burnett, 1996), and promote immunity and intestinal health (Zou et al., 2006). However, there is little information on the effect of exogenous enzymes in starter diet on the intestinal microflora and gut morphology of broiler chicks, especially in diets based on corn and soybean meal.

The objective of this study was to determine the effects of increasing the density of nutrients (protein, essential amino acids, $\mathrm{Ca}$, and P) in the starter diet and the addition or not of feed additives on broiler performance, intestinal microflora, gut morphology, and immune response.

\section{MATERIAL AND METHODS}

\section{Bird management and diets}

A total of 810 one-d-old, straight-run Ross 308 broiler chicks were obtained from a commercial hatchery, and individually weighed (average initial body weight of $48 \mathrm{~g}$ ). Birds were housed in pens $(100 \times 100 \times 70 \mathrm{~cm}, L \times W \times H)$ equipped with two nipple drinkers and a hanging plastic feeder each for manual feed distribution. The pen's concrete floor was covered with new wood-shaving litter. All birds had free access to feed and water, and were exposed to 23L:1D throughout the trial. Temperature was initially set at $32^{\circ} \mathrm{C}$ on $\mathrm{d} 1$ and linearly decreased by $0.5^{\circ} \mathrm{C}$ per day to reach a temperature of $21^{\circ} \mathrm{C}$ on $\mathrm{d} 22$ and kept constant thereafter. All birds were vaccinated against the viral diseases Newcastle and Infectious Bursal (IBD), as scheduled by the local veterinary officials.

Birds were distributed based on a completely randomized design experiment with a $3 \times 3$ factorial arrangement, totaling of nine treatments, with six replicate pens of 15 birds each. Nine broiler starter diets were formulated to evaluate three dietary nutrient densities and the inclusion of three feed additives. Firstly, three starter broiler diets were formulated with nutrient densities of $100,103.75$, and $107.5 \%$ of the nutritional requirements as recommended by the Aviagen (Ross 308, 2014). Then, the diets with each nutrient density were divided into three equal portions and supplied with no feed additives (FA), with Maxi-Gen ${ }^{\text {TM }}$ Plus at the rate of $0.5 \mathrm{~g} / \mathrm{kg}$ diet, or with the combination of Maxi-Gen ${ }^{\mathrm{TM}}$ Plus + Superzyme ${ }^{\mathrm{TM}}$ CS+Bio-Phytase 5000Gat rates of $0.5,0.25$ and 0.1 $\mathrm{g} / \mathrm{kg}$ diet, respectively (Canadian Bio-Systems Inc., Calgary, Alberta, Canada), and mixed in a mixer. The commercial additive Maxi-Gen ${ }^{\mathrm{TM}}$ Plus contains $10 \%$ moisture, $28 \%$ crude protein, $1.5 \%$ nucleotides, and $22 \%$ yeast carbohydrates. The enzyme blend (Superzyme ${ }^{\text {TM }}$-CS 2X) contains $11 \%$ moisture, 12\% crude protein, $5 \%$ crude fiber, 2400 xylanase units $/ g$, 300 glucanase units/g, 1400 invertase units/g, 2400 protease units/g, 1000 cellulase units/g, 24000 amylase units/g, and 120 mannanase units/g. The phytase product (Bio-Phytase) contains 5000 phytase units/g. The ingredients and chemical composition of the starter diets are shown in Table 1. The experimental protocol was approved by the Animal Welfare Committee, at the Ferdowsi University of Mashhad, Iran.

\section{Performance}

Birds were weighed per replicate upon arrival and on d 5, 10, 24 and 42, using a digital electronic balance at $0.1 \mathrm{~g}$ accuracy to record body weight (BW). Feed intake $(\mathrm{Fl})$ was determined as the difference between feed supply and feed residue during each period. Mortality was recorded as it occurred, and the weight of individual dead birds was added to the total pen live body weight for the calculation of feed conversion ratio (FCR) during each period. The FCR were calculated by dividing total feed intake by body weight gain (BWG) of birds.

\section{Sample collection and measurements}

One chick per replicate, with BW close to the average pen weight, was randomly selected for the evaluation of the intestinal microflora and gut 
Table 1 - Ingredients and nutrient composition of the starter diets ${ }^{1}$ fed from 1 to 10 days of age

\begin{tabular}{|c|c|c|c|c|c|c|c|c|c|}
\hline \multirow[b]{3}{*}{ Ingredient (\%) } & \multicolumn{9}{|c|}{ Nutrient density (\% of recommendation) } \\
\hline & \multicolumn{3}{|c|}{100.00} & \multicolumn{3}{|c|}{103.75} & \multicolumn{3}{|c|}{107.50} \\
\hline & No additive & Maxi & $(\mathrm{Maxi}+\mathrm{Sz}+\mathrm{P})^{2}$ & No additive & Maxi & $\mathrm{Maxi}+\mathrm{Sz}+\mathrm{P}$ & No additive & Maxi & $\mathrm{Maxi}+\mathrm{Sz}+\mathrm{P}$ \\
\hline Corn $8.5 \%$ & 39.80 & 39.80 & 39.80 & 39.53 & 39.53 & 39.53 & 38.70 & 38.70 & 38.70 \\
\hline Brokenrice & 18.00 & 18.00 & 18.00 & 19.50 & 19.50 & 19.50 & 19.96 & 19.96 & 19.96 \\
\hline Soybeanmeal $46 \%$ & 19.34 & 19.34 & 19.34 & 21.78 & 21.78 & 21.78 & 16.44 & 16.44 & 16.44 \\
\hline ISP3 $90 \%$ & 4.50 & 4.50 & 4.50 & 5.00 & 5.00 & 5.00 & 8.00 & 8.00 & 8.00 \\
\hline Cornglutenmeal $60 \%$ & 7.53 & 7.53 & 7.53 & 7.79 & 7.79 & 7.79 & 9.00 & 9.00 & 9.00 \\
\hline Soybeanoil & 0.92 & 0.92 & 0.92 & 1.74 & 1.74 & 1.74 & 3.00 & 3.00 & 3.00 \\
\hline Wheatbran15\% & 4.42 & 4.42 & 4.42 & - & - & - & - & - & - \\
\hline Casein $80 \%$ & 1.00 & 1.00 & 1.00 & - & - & - & - & - & - \\
\hline Dicalciumphosphate & 1.66 & 1.66 & 1.66 & 1.81 & 1.81 & 1.81 & 1.96 & 1.96 & 1.96 \\
\hline Calciumcarbonate & 1.42 & 1.42 & 1.42 & 1.44 & 1.44 & 1.44 & 1.46 & 1.46 & 1.46 \\
\hline Sodiumchloride & 0.38 & 0.38 & 0.38 & 0.41 & 0.41 & 0.41 & 0.42 & 0.42 & 0.42 \\
\hline L-lysine-HCl & 0.25 & 0.25 & 0.25 & 0.22 & 0.22 & 0.22 & 0.26 & 0.26 & 0.26 \\
\hline DL-methionine & 0.24 & 0.24 & 0.24 & 0.24 & 0.24 & 0.24 & 0.25 & 0.25 & 0.25 \\
\hline Threonine & 0.04 & 0.04 & 0.04 & 0.04 & 0.04 & 0.04 & 0.05 & 0.05 & 0.05 \\
\hline Vit.+min.premix ${ }^{4}$ & 0.50 & 0.50 & 0.50 & 0.50 & 0.50 & 0.50 & 0.50 & 0.50 & 0.50 \\
\hline \multicolumn{10}{|c|}{ Calculated nutrients (\% unless stated) } \\
\hline $\mathrm{ME}(\mathrm{MJ} / \mathrm{Kg})$ & 12.55 & 12.55 & 12.55 & 13.02 & 13.02 & 13.02 & 13.49 & 13.49 & 13.49 \\
\hline Crudeprotein $^{5}$ & 22.93 & 22.87 & 22.95 & 23.85 & 23.88 & 23.80 & 24.87 & 24.80 & 24.85 \\
\hline Lysine & 1.29 & 1.29 & 1.29 & 1.34 & 1.34 & 1.34 & 1.39 & 1.39 & 1.39 \\
\hline Methionine & 0.65 & 0.65 & 0.65 & 0.67 & 0.67 & 0.67 & 0.70 & 0.70 & 0.70 \\
\hline Met+cys & 0.95 & 0.95 & 0.95 & 0.97 & 0.97 & 0.97 & 1.00 & 1.00 & 1.00 \\
\hline Threonine & 0.90 & 0.90 & 0.90 & 0.93 & 0.93 & 0.93 & 0.97 & 0.97 & 0.97 \\
\hline Calcium & 0.96 & 0.96 & 0.96 & 1.00 & 1.00 & 1.00 & 1.03 & 1.03 & 1.03 \\
\hline AvailableP & 0.48 & 0.48 & 0.48 & 0.50 & 0.50 & 0.50 & 0.52 & 0.52 & 0.52 \\
\hline
\end{tabular}

${ }^{1}$ Similar commercial corn-soy grower and finisher diets were fed to all birds from 10-24 and 24-42 days of age, respectively. 2 (Maxi-GenTM Plus, SuperzymeTM-CS 2X, Bio-Phytase 5000G, at the rate of 0.5, 0.25 and $0.1 \mathrm{~g} / \mathrm{kg}$ diet, respectively). 3lsolated soy protein (Shangdong Yuxin Bio-Tech Co., Qingdao, China). 4 Each kg of diet contained: IU: vit. A 9000, vit. D3 2000, vit. E 18; mg: vit. K3 2, vit. B1 1.8, vit. B2 6.6, vit. B3 10, vit. B5 30, vit. B6 3, vit. B9 1, vit. B12 0.015, vit. H2 0.1, choline choloride 500; Mn 100, Fe 50, Zn 100, Cu 10, Mg 3.5, Se 0.2. 5 Analyzed values.

morphology on days 5 and 10 of age. The selected birds were weighed, sacrificed, dissected, and the ileal and/or caeca (mixture of both caecum) content of each bird was immediately collected, mixed, placed in a microtube, and stored at $-70^{\circ} \mathrm{C}$ until microbial analysis.

Microbial populations were determined by serial dilution of the ileal and/or cecal samples in anaerobic diluents before inoculation onto Petri dishes with sterile agar. Lactobacilli were grown on Rogosa SL agar, Bifidobacteria on BIM-25 agar, and E. coli on EMB agar. Lactobacilli and Bifidobacteria plates were anaerobically incubated at $37^{\circ} \mathrm{C}$ for $48 \mathrm{~h}$, and $E$. coli plates were aerobically incubated at $37^{\circ} \mathrm{C}$ for $24 \mathrm{~h}$, after which colony-forming units (UFC) of each were counted and expressed as in common logarithms of CFU per gram of fresh ileal and/or cecal content.

Subsequently, the mid-section of duodenum, jejunum, and ileum $\left(1 \mathrm{~cm}^{2}\right)$ were collected, gently washed with physiological saline solution to remove any adherent of intestinal content, and the poured into duly identified flasks with 10\% buffered formalin for histological study. Formalin solutions were changed two times to refresh the tissues. Tissue samples dehydrated with increasing concentrations (70, 80, 95 , and $100 \%$ ) of ethanol, cleared with xylene, and embedded in paraffin wax. Tissue sections $(2 \mu \mathrm{m})$ were cut using a microtome (Pouyan, MK 1120, Pouyan Co., Mashhad, Iran), mounted onto slides, and stained with hematoxylin (Gill no. 2, Sigma, St. Louis, MO) and eosin (Sigma). Twelve images from three sections of each tissue sample were taken, and 24 villus heights and crypt depths were measured using animage ProPlus V 4.5software (Model U- TV0.5 XC-2, Olympus Corporation, BX41, Olympus, Tokyo, Japan). Villus length was measured from the tip of the villus to the valley between individual villi, and measurements for crypt depth were taken from the valley between individual villi and the basolateral membrane.

\section{Evaluation of humoral immune response}

Total antibody titers against sheep red blood cells (SRBC) were measured using hemagglutination test. About $20 \mathrm{~mL}$ blood of a male sheep were collected into labeled sterile tubes containing EDTA, centrifuged for 
15 min at 2000 rpm, the supernatant was discarded, the precipitate was washed three times in phosphate buffer solution (PBS), and diluted in PBS to 15\% (vol/ vol) to provide the SRBC. Two chicks per replicate were intramuscularly injected with $1 \mathrm{~mL}$ of the $15 \%$ SRBC suspension at 28 and $35 \mathrm{~d}$ of age. Sera were collected seven days after the immune challenge in 35 and $42 \mathrm{~d}$ of age. The serum from each sample was collected, heat inactivated at $56^{\circ} \mathrm{C}$ for $30 \mathrm{~min}$, and then analyzed for total, mercaptoethanol-resistant (MER), and mercaptoethanol-sensitive (MES) antibody titers. The MER and MES titers are presumably $\lg G$ and $\lg M$, respectively. Fifty $\mu \mathrm{L}$ of serum was added in an equal amount of PBS in the first column of a 96-well $V$-shaped bottom plate, and the solution was incubated for $30 \mathrm{~min}$ at $37^{\circ} \mathrm{C}$. A serial dilution was then made $(1: 2)$, and $50 \mu \mathrm{L}$ of $2 \%$ SRBC suspension was added to each well. Total antibody titers were then read after 30 min of incubation at $37^{\circ} \mathrm{C}$. The well immediately preceding a well with a distinct SRBC at the button was considered as the endpoint titer for agglutination. For IgM response, $50 \mu \mathrm{L}$ of $0.01 \mathrm{M}$ mercaptoethanol in PBS was used instead of PBS alone, followed by the aforementioned procedure. The difference between total and IgG titers was considered to be equal to the IgM antibody titer.

\section{Statistical analysis}

Data were analyzed in a completely randomized design with factorial arrangement, using the GLM procedure of SAS software (SAS Institute, 2008). Means were compared by Duncan's multiple-range test. Difference among means was considered significant at probability level of equal or lower than $5 \%$. Data were also subjected to orthogonal polynomial analysis for linear and quadratic trends, using SAS software (SAS Institute, 2008).

\section{RESULTS AND DISCUSSION}

\section{Performance}

The main effects of nutrient densities (ND) and feed additives (FA) in starter diet and their interaction on broiler performance are shown in Table 2 . The increase in the ND of the starter diet increased $(p<0.05)$ the BWG of birds during all periods, except for those fed the $103.75 \%$ ND diet from 1-5 d of age. The chicks fed starter diet supplemented with both feed additives presented higher $(p<0.0001)$ BWG compared with the control birds at $42 \mathrm{~d}$ of age. The chicks fed the $103.75 \%$ ND diet and the combination of additives, and those fed the $107.5 \%$ ND diet with the combination of FA presented similar BWG than those fed the control or other diets at $10 \mathrm{~d}$ of age. Chicks fed the 107.5\% ND diet with the FA and the FA combination presented higher $(p<0.05)$ BWG than those fed the control or other diets at $42 \mathrm{~d}$ of age. The chicks fed the $107.5 \%$ ND diet presented lower $(p<0.0001)$ FCR than those fed the control diet (100\% of the requirements) during the entire rearing period (1-42 d of age). The starter diet containing the combination of feed additives improved $(p<0.05)$ the FCR compared with those fed the control diet during 1-24 and/or 1-42 d of age. The effect of nutrient density diet showed that chicks fed starter diet with $107.5 \%$ ND and supplemented with the FA combination had lower $(p<0.05)$ FCR compared with those fed the control (1.662 vs. 1.727) and/ or other diets with the exception of those fed the $107.5 \%$ ND diet and supplemented with Maxi-Gen during 1-42 d of age. Powell et al. (2016) reported that methionine concentration in the pre-starter diet did not have a significant effect on FI, BWG and FCR during 0 to 7 or 0 to $42 \mathrm{~d}$ of age. Similarly, Zhai et al. (2014) reported that amino acid (AA) density did not have a significant effect on FI, BWG, and FCR. In contrast, other studies have stated that high AA density improves FCR (Wang et al., 2015; Gottardo et al., 2016), and BWG (Wang et al., 2015). Also, it has been reported that the increase in ND of the starter diet enhanced growth rate in all growing periods (Zhai et al., 2013) and improved economic efficiency (Sklan \& Noy, 2003). Amino acids act as signal mediators of protein synthesis, such that a high protein pre-starter diet can up regulate the initiation of protein translation in broiler breast muscle (Everaert et al., 2010). Hence, the optimization of dietary AA density in the first week of post-hatch is an important consideration for long-term muscle growth. Cowieson et al. (2017) reported that the beneficial effects of exogenous protease in diet based on SBM may be due to a reduction in the allergenicity of antigenic proteins, reducing intestinal inflammation. The beneficial effects of exogenous protease may be related to increase in protein and energy digestibility and also improving gut morphological characteristics (Cowieson et al., 2017).

\section{Intestinal microflora counts}

The effect of starter diets containing different levels of ND and FA on microflora counts in the ileal and cecal digesta of broiler chicks on d 10 (log10 cfu/g content) are shown in Table 3. There was no interaction between ND and FA on microflora counts, and therefore, only 
Table 2 - Effect of starter diet contained three nutrient densities (ND) and different feed additives (FA) on performance of broiler chickens ${ }^{1}$

\begin{tabular}{|c|c|c|c|c|c|c|c|c|c|}
\hline \multirow[t]{2}{*}{ ND \% } & \multirow[t]{2}{*}{ FA } & \multicolumn{4}{|c|}{ Weight gain (g/chick) } & \multicolumn{4}{|c|}{ Feed conversion ratio $(\mathrm{g} / \mathrm{g})$} \\
\hline & & $1-5 d$ & $1-10 d$ & $1-24 d$ & $1-42 d$ & $1-5 d$ & $1-10 d$ & $1-24 d$ & $1-42 d$ \\
\hline 100.00 & No & $104^{c}$ & $215^{c}$ & $923^{d}$ & $2471^{d}$ & $0.645^{\mathrm{ab}}$ & $0.934^{\mathrm{a}}$ & $1.220^{\mathrm{ab}}$ & $1.727^{a}$ \\
\hline 100.00 & Maxi $^{2}$ & $108^{b c}$ & $221^{b}$ & $928^{\text {cd }}$ & $2474^{d}$ & $0.618^{a b c}$ & $0.918^{\mathrm{ab}}$ & $1.228^{a}$ & $1.726^{a}$ \\
\hline 100.00 & $(\mathrm{Mx}+\mathrm{Sz}+\mathrm{P})^{3}$ & $107^{b c}$ & $220^{b}$ & $64^{\mathrm{ab}}$ & $2499^{b c d}$ & $0.659^{a}$ & $0.933^{a}$ & $1.180^{\circ}$ & $1.717^{\mathrm{a}}$ \\
\hline 103.75 & No & $107^{\mathrm{bc}}$ & $221^{b}$ & $967^{\mathrm{ab}}$ & $2495^{\mathrm{cd}}$ & $0.608^{\mathrm{abc}}$ & $0.910^{\mathrm{abc}}$ & $1.716^{\mathrm{a}}$ & $1.177^{c}$ \\
\hline 103.75 & Maxi & $105^{c}$ & $219^{b c}$ & $953^{\mathrm{bc}}$ & $2516^{b c}$ & $0.610^{\mathrm{abc}}$ & $0.913^{\mathrm{abc}}$ & $1.190^{\mathrm{bc}}$ & $1.715^{a}$ \\
\hline 103.75 & $(\mathrm{Mx}+\mathrm{Sz}+\mathrm{P})$ & $111^{\mathrm{ab}}$ & $231^{a}$ & $967^{a b}$ & $2538^{b}$ & $0.618^{\mathrm{abc}}$ & $0.886^{\text {bcd }}$ & $1.185^{b c}$ & $1.706^{\mathrm{ab}}$ \\
\hline 107.50 & No & $110^{\mathrm{ab}}$ & $229^{a}$ & $959^{a b}$ & $2539^{b}$ & $0.600^{b c}$ & $0.880^{c d}$ & $1.193^{\mathrm{abc}}$ & $1.702^{\mathrm{ab}}$ \\
\hline 107.50 & Maxi & $111^{\mathrm{ab}}$ & $234^{\mathrm{a}}$ & $987^{a}$ & $2609^{a}$ & $0.610^{\mathrm{abc}}$ & $0.871^{d}$ & $1.163^{c}$ & $1.679^{b c}$ \\
\hline 107.50 & $(\mathrm{Mx}+\mathrm{Sz}+\mathrm{P})$ & $112^{\mathrm{a}}$ & $232^{\mathrm{a}}$ & $987^{a}$ & $2623^{a}$ & $0.581^{c}$ & $0.873^{d}$ & $1.155^{c}$ & $1.662^{c}$ \\
\hline $\mathrm{SEM}^{4}$ & & 1.28 & 1.65 & 8.99 & 13.12 & 0.017 & 0.011 & 0.012 & 0.010 \\
\hline \multicolumn{10}{|c|}{ Main Effect Means ${ }^{5}$} \\
\hline \multicolumn{10}{|c|}{$\mathrm{ND}$} \\
\hline 100.00 & & $107^{b}$ & $219^{c}$ & $938^{c}$ & $2481^{c}$ & $0.641^{a}$ & $0.931^{a}$ & $1.209^{a}$ & $1.724^{a}$ \\
\hline 103.75 & & $108^{b}$ & $224^{b}$ & $963^{b}$ & $2516^{b}$ & $0.612^{b}$ & $0.903^{b}$ & $1.184^{b}$ & $1.712^{\mathrm{a}}$ \\
\hline 107.50 & & $111^{a}$ & $231^{a}$ & $978^{a}$ & $2591^{a}$ & $0.597^{b}$ & $0.875^{c}$ & $1.171^{\mathrm{b}}$ & $1.681^{b}$ \\
\hline \multicolumn{10}{|c|}{ FA } \\
\hline & No & $107^{b}$ & $221^{c}$ & $950^{b}$ & $2502^{b}$ & 0.618 & 0.910 & $1.197^{a}$ & $1.715^{a}$ \\
\hline & Maxi & $108^{\mathrm{ab}}$ & $225^{b}$ & $956^{b}$ & $2533^{a}$ & 0.613 & 0.901 & $1.194^{\mathrm{a}}$ & $1.706^{\mathrm{ab}}$ \\
\hline & $(\mathrm{Mx}+\mathrm{Sz}+\mathrm{P})$ & $110^{a}$ & $228^{a}$ & $973^{a}$ & $2553^{a}$ & 0.619 & 0.897 & $1.173^{b}$ & $1.695^{b}$ \\
\hline SEM & & 0.74 & 0.95 & 5.19 & 7.57 & 0.010 & 0.006 & 0.007 & 0.006 \\
\hline \multicolumn{10}{|l|}{$p$-value } \\
\hline ND & & 0.0001 & $<.0001$ & $<.0001$ & $<.0001$ & 0.010 & $<.0001$ & 0.001 & $<.0001$ \\
\hline FA & & 0.027 & $<.0001$ & 0.009 & $<.0001$ & 0.889 & 0.288 & 0.049 & 0.051 \\
\hline $\mathrm{ND} \times \mathrm{FA}$ & & 0.0003 & $<.0001$ & $<.0001$ & $<.0001$ & 0.093 & 0.0001 & 0.002 & 0.0001 \\
\hline \multicolumn{10}{|c|}{ Orthogonal polynomials } \\
\hline \multicolumn{10}{|c|}{ ND } \\
\hline Linear & & 0.003 & $<.0001$ & $<.0001$ & $<.0001$ & 0.004 & $<.0001$ & 0.001 & 0.0003 \\
\hline Quadratic & & $<.001$ & $<.0001$ & 0.048 & $<.0001$ & 0.297 & 0.003 & 0.191 & 0.0003 \\
\hline \multicolumn{10}{|l|}{ FA } \\
\hline Linear & & 0.044 & 0.0002 & 0.024 & $<.0001$ & 0.893 & 0.129 & 0.140 & 0.043 \\
\hline Quadratic & & 0.066 & 0.013 & 0.028 & 0.066 & 0.643 & 0.687 & 0.046 & 0.159 \\
\hline
\end{tabular}

${ }^{1}$ All birds were fed a similar corn-soy commercial grower and finisher diets during 10-24 and 24-42 d of age, respectively. a, b, ... Means in the same column with no common superscript for each effect are significantly different at $p \leq 0.05$. 2 Maxi-GenTM Plus at the rate of $0.5 \mathrm{~g} / \mathrm{kg}$ diet. 3 (Maxi-GenTM Plus, SuperzymeTM-CS 2 X, Bio-Phytase 5000G at the rate of $0.5,0.25$ and $0.1 \mathrm{~g} / \mathrm{kg}$ diet, respectively). 4 Standard error of the mean. 5 Mean of 15 birds per pen, 18 pens per diet.

the main effects are presented. The ND and FA did not have any effect ( $p>0.05)$ on E. coli, Lactobacillii or Bifidobacteria counts in the ileal content or on E. coli counts in the cecal content. On the other hand, the increase in ND linearly increased $(p=0.007)$ Lactobacilli counts in cecal content of 10-d-old chicks. Feeding starter diet containing different ND caused a linear increase $(p=0.039)$ in Bifidobacteria counts in cecal content of $10 \mathrm{~d}$ chicks. The dietary inclusion of the additive and the combination of additives significantly increased Lactobacilli and Bifidobacteria counts in the cecal content at $10 \mathrm{~d}$ of age. There was no effect of the treatments on the microflora counts in the ileal content of 10-d-old chicks. Similarly, Yang et al. (2007) did not find any significant differences in the small intestine microflora counts in broilers fed a range of FA including probiotics, organic acids, mannan oligosaccharides, and antibiotics. Kim et al. (2016) reported that dietary ND did not have any effect on the cecal microflora counts of broiler chickens. The current study showed that the starter diet ND or FA supplementation significantly increased Bifidobacteria counts and decreased E. coli counts in the cecal content. The ceca is the main fermentative chamber of broiler chickens and, in comparison with other gastrointestinal tract segments, contains the largest number of bacteria, and present high ability to ferment carbohydrates (Józefiak et al., 2004). Exogenous enzymes increase the levels of substrate available for microbial fermentation and the production of short chain fatty acids (SCFA) in the cecum (Choct et al., 1996). Increasing SCFA density causes a gradual decrease in the proliferation rate of Enterobacteria, but not that of Lactobacilli (Van der Wielen et al., 2000). 
Table 3 - Effect of starter diet containing three nutrient densities (ND) and different feed additives (FA) on microflora counts in the ileal and cecal contents of 10-d-old chicks (log10 cfu/g content)

\begin{tabular}{|c|c|c|c|c|c|c|}
\hline \multirow[b]{2}{*}{ Treatments } & \multicolumn{3}{|c|}{ Ileum } & \multicolumn{3}{|c|}{ Caeca } \\
\hline & E. coli & Lactobacillus & Bifidobacteria & E. coli & Lactobacillus & Bifidobacteria \\
\hline \multicolumn{7}{|c|}{ ND\% (as recommended) } \\
\hline 100.00 & 4.487 & 6.693 & 6.121 & 4.776 & $7.304^{b}$ & $6.379^{b}$ \\
\hline 103.75 & 4.658 & 6.771 & 6.092 & 4.786 & $7.734^{\mathrm{a}}$ & $6.540^{\mathrm{ab}}$ \\
\hline 107.50 & 4.527 & 6.605 & 5. 902 & 4.854 & $7.667^{a}$ & $6.766^{a}$ \\
\hline \multicolumn{7}{|l|}{ FA } \\
\hline No additive & 4.602 & 6.731 & 6.064 & 4.780 & $7.199^{b}$ & $6.340^{b}$ \\
\hline Maxi & 4.619 & 6.686 & 6.048 & 4.861 & $7.815^{\mathrm{a}}$ & $6.685^{a}$ \\
\hline$(\mathrm{Maxi}+\mathrm{Sz}+\mathrm{P})^{1}$ & 4.451 & 6.652 & 6.003 & 4.776 & $7.691^{\mathrm{a}}$ & $6.660^{\mathrm{a}}$ \\
\hline SEM & 0.099 & 0.071 & 0.082 & 0.093 & 0.114 & 0.105 \\
\hline \multicolumn{7}{|l|}{$p$-value } \\
\hline ND & 0.4515 & 0.2713 & 0.1349 & 0.8100 & 0.0224 & 0.0419 \\
\hline FA & 0.4245 & 0.7372 & 0.8630 & 0.7645 & 0.0009 & 0.0440 \\
\hline$N D \times F A$ & 0.1200 & 0.0696 & 0.0829 & 0.9042 & 0.2016 & 0.3513 \\
\hline \multicolumn{7}{|c|}{ Orthogonal polynomials } \\
\hline \multicolumn{7}{|c|}{ ND } \\
\hline Linear & 0.3922 & 0.9497 & 0.2246 & 0.6990 & 0.0066 & 0.0392 \\
\hline Quadratic & 0.3552 & 0.1084 & 0.1090 & 0.6046 & 0.6784 & 0.1361 \\
\hline \multicolumn{7}{|l|}{ FA } \\
\hline Linear & 0.5814 & 0.4809 & 0.7010 & 0.7371 & 0.0003 & 0.0131 \\
\hline Quadratic & 0.2367 & 0.7431 & 0.7039 & 0.5170 & 0.4458 & 0.8672 \\
\hline
\end{tabular}

${ }^{1}$ (Maxi-Gen ${ }^{\text {TM }}$ Plus, Superzyme ${ }^{\text {TM }}$ CS $2 X$, Bio-Phytase $5000 \mathrm{G}$ at the rate of $0.5,0.25$ and $0.1 \mathrm{~g} / \mathrm{kg}$ diet, respectively). a, ${ }^{\mathrm{b}}$ Means in the same column with no common superscript for each effect are significantly different at $p \leq 0.05$. SEM $=$ standard error of the mean.

Table 4 - Effect of three nutrient densities (ND) and different feed additives (FA) in starter diet on intestinal morphology of 5 and $10 \mathrm{~d}$ chicks

\begin{tabular}{|c|c|c|c|c|c|c|c|c|c|c|c|c|}
\hline \multirow[b]{3}{*}{ Treatments } & \multicolumn{6}{|c|}{ Villus height $(\mu \mathrm{m})$} & \multicolumn{6}{|c|}{ Villus height to crypt depth ratio } \\
\hline & \multicolumn{2}{|c|}{ Duodenum } & \multicolumn{2}{|c|}{ Jejunun } & \multicolumn{2}{|c|}{ Ilenum } & \multicolumn{2}{|c|}{ Duodenum } & \multicolumn{2}{|c|}{ Jejunun } & \multicolumn{2}{|c|}{ Ilenum } \\
\hline & $5 d$ & $10 \mathrm{~d}$ & $5 d$ & $10 \mathrm{~d}$ & $5 d$ & $10 \mathrm{~d}$ & $5 d$ & $10 \mathrm{~d}$ & $5 d$ & $10 \mathrm{~d}$ & $5 d$ & $10 \mathrm{~d}$ \\
\hline \multicolumn{13}{|c|}{ ND\% (as recommended) } \\
\hline 100.00 & $999^{b}$ & $1178^{b}$ & $708^{c}$ & $829^{b}$ & $435^{b}$ & $525^{c}$ & $5.52^{c}$ & $6.47^{b}$ & $4.37^{c}$ & $4.98^{c}$ & $3.39^{\mathrm{b}}$ & $4.04^{c}$ \\
\hline 103.75 & $1041^{\mathrm{a}}$ & $1193^{a}$ & $757^{b}$ & $847^{b}$ & $454^{\mathrm{ab}}$ & $533^{b}$ & $5.96^{b}$ & $6.85^{\mathrm{a}}$ & $4.98^{b}$ & $5.53^{b}$ & $3.68^{\mathrm{a}}$ & $4.26^{\mathrm{b}}$ \\
\hline 107.50 & $1060^{a}$ & $1193^{a}$ & $784^{a}$ & $866^{a}$ & $462^{\mathrm{a}}$ & $542^{a}$ & $6.46^{a}$ & $7.15^{\mathrm{a}}$ & $5.80^{\mathrm{a}}$ & $5.99^{a}$ & $3.83^{\mathrm{a}}$ & $4.47^{a}$ \\
\hline \multicolumn{13}{|l|}{ FA } \\
\hline No additive & $1017^{b}$ & 1184 & $735^{b}$ & 843 & 441 & 531 & $5.82^{b}$ & 6.69 & 4.90 & 5.38 & 3.54 & $4.17^{b}$ \\
\hline Maxi & $1032^{\mathrm{ab}}$ & 1189 & $749^{a b}$ & 855 & 454 & 534 & $5.93^{\mathrm{ab}}$ & 6.87 & 5.04 & 5.46 & 3.62 & $4.24^{\mathrm{ab}}$ \\
\hline$(\mathrm{Maxi}+\mathrm{Sz}+\mathrm{P})^{1}$ & $1051^{a}$ & 1190 & $765^{a}$ & 844 & 456 & 536 & $6.19^{a}$ & 6.92 & 5.22 & 5.66 & 3.73 & $4.36^{a}$ \\
\hline SEM & 7.14 & 2.15 & 7.22 & 6.70 & 7.05 & 1.75 & 0.10 & 0.12 & 0.13 & 0.12 & 0.08 & 0.05 \\
\hline \multicolumn{13}{|l|}{$p$-value } \\
\hline ND & $<.0001$ & $<.0001$ & $<.0001$ & 0.001 & 0.027 & $<.0001$ & $<.0001$ & 0.001 & $<.0001$ & $<.0001$ & 0.001 & $<.0001$ \\
\hline FA & 0.005 & 0.100 & 0.018 & 0.389 & 0.283 & 0.127 & 0.040 & 0.332 & 0.241 & 0.254 & 0.197 & 0.029 \\
\hline$N D \times F A$ & 0.669 & 0.139 & 0.375 & 0.573 & 0.705 & 0.482 & 0.397 & 0.571 & 0.153 & 0.189 & 0.630 & 0.369 \\
\hline \multicolumn{13}{|c|}{ Orthogonal polynomials } \\
\hline \multicolumn{13}{|c|}{ ND } \\
\hline Linear & $<.0001$ & $<.0001$ & $<.0001$ & $<.0001$ & 0.001 & $<.0001$ & $<.0001$ & 0.001 & $<.0001$ & $<.0001$ & 0.0003 & $<.0001$ \\
\hline Quadratic & 0.073 & 0.957 & 0.012 & 0.048 & 0.426 & 0.001 & 0.001 & 0.075 & $<.0001$ & 0.011 & 0.150 & 0.004 \\
\hline \multicolumn{13}{|l|}{ FA } \\
\hline Linear & 0.006 & 0.034 & 0.016 & 0.472 & 0.117 & 0.055 & 0.061 & 0.151 & 0.158 & 0.233 & 0.129 & 0.037 \\
\hline Quadratic & 0.064 & 0.828 & 0.115 & 0.242 & 0.846 & 0.505 & 0.079 & 0.724 & 0.354 & 0.250 & 0.330 & 0.086 \\
\hline
\end{tabular}

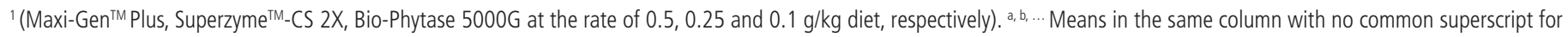
each effect are significantly different at $p \leq 0.05$. SEM $=$ standard error of the mean. 


\section{Intestinal morphology}

Effect of the starter diet containing different ND and FA on the intestinal morphology of broiler chicks at 5 and $10 \mathrm{~d}$ of age are shown in Table 4. There was no interaction between ND and FA on intestinal morphology, and thus the main effects are presented. Villus height and villus height to crypt depth ratio (VCR) in the duodenum and jejunum increased $(p<0.05)$ when chicks fed starter diet containing $103.75 \%$ and $107.5 \% \mathrm{ND}$ at 5 and $10 \mathrm{~d}$ of age. Feeding starter diet containing the additive combination increased $(p<0.05)$ villus height in the duodenum and jejunum of 5 -d-old chicks. The inclusion of FA in the starter diet linearly increased $(p<0.055)$ villus height in ileum at $10 \mathrm{~d}$ of age. The VCR in jejunum was not affected by additive supplementation at 5 or $10 \mathrm{~d}$ of age, but the supplementation with the additive combination increased $(p<0.05)$ the VCR in the duodenum and ileum at 5 and $10 \mathrm{~d}$ of age, respectively. The inclusion of Maxi-Gen alone in starter diet did not have a significant effect on intestinal morphology of broiler chicks at 5 or $10 \mathrm{~d}$ of age. Chen et al. (2016) reported that higher dietary levels of branched-chain amino acids increased villus height $(p=0.08$ ) of the jejunum of broiler chickens at $20 \mathrm{~d}$ of age. In contrast, Wang et al. (2015) reported that dietary protein source and ND did not have any effect on the length of small intestine and intestinal morphology. Zhu et al. (2014) reported that enzyme supplementation improved intestinal morphology in broiler chickens. Our data showed that enzyme supplementation increased duodenum, jejunum and ileum villus height at 5 and/or $10 \mathrm{~d}$ chicks. Increased villus height may indicate a general increase in the digestive and absorptive capacity of the small intestine in

Table 5 - Effect of three nutrient densities (ND) and different feed additives (FA) in starter diet on total anti-SRBC, IgG, and IgM titers of 35 and $42 \mathrm{~d}$ broiler chickens

\begin{tabular}{|c|c|c|c|c|c|c|c|}
\hline \multirow[b]{2}{*}{ ND \% } & \multirow[b]{2}{*}{ FA } & \multicolumn{2}{|c|}{ Total anti-SRBC (mg/dL) } & \multicolumn{2}{|c|}{$\operatorname{lgG}(\mathrm{mg} / \mathrm{dL})$} & \multicolumn{2}{|c|}{$\lg \mathrm{M}(\mathrm{mg} / \mathrm{dL})$} \\
\hline & & $35 d$ & $42 d$ & $35 d$ & $42 d$ & $35 d$ & $42 d$ \\
\hline 100.00 & No & $6.33^{c}$ & $7.83^{\mathrm{bc}}$ & $4.00^{b}$ & $5.33^{\mathrm{cd}}$ & $2.33^{b}$ & 2.50 \\
\hline 100.00 & Maxi $^{1}$ & $6.33^{c}$ & $8.00^{\mathrm{abc}}$ & $4.50^{\mathrm{ab}}$ & $5.17^{d}$ & $1.83^{b}$ & 2.83 \\
\hline 100.00 & $(\mathrm{Mx}+\mathrm{Sz}+\mathrm{P})^{2}$ & $7.83^{\mathrm{ab}}$ & $8.50^{\mathrm{abc}}$ & $5.83^{a}$ & $6.50^{\mathrm{ab}}$ & $2.00^{b}$ & 2.00 \\
\hline 103.75 & No & $6.83^{b c}$ & $9.00^{\mathrm{ab}}$ & $5.33^{\mathrm{ab}}$ & $6.33^{\mathrm{abc}}$ & $1.50^{\mathrm{b}}$ & 2.67 \\
\hline 103.75 & Maxi & $7.00^{\mathrm{bc}}$ & $8.00^{\mathrm{abc}}$ & $4.50^{\mathrm{ab}}$ & $5.33^{\mathrm{cd}}$ & $2.50^{b}$ & 2.67 \\
\hline 103.75 & $(\mathrm{Mx}+\mathrm{Sz}+\mathrm{P})$ & $7.00^{\mathrm{bc}}$ & $8.50^{\mathrm{abc}}$ & $4.50^{\mathrm{ab}}$ & $5.67^{\mathrm{bcd}}$ & $2.50^{\mathrm{b}}$ & 2.83 \\
\hline 107.50 & No & $6.67^{b c}$ & $7.67^{c}$ & $4.33^{\mathrm{ab}}$ & $5.83^{\mathrm{abc}}$ & $2.33^{b}$ & 1.83 \\
\hline 107.50 & Maxi & $7.33^{\mathrm{abc}}$ & $9.17^{\mathrm{a}}$ & $5.50^{\mathrm{ab}}$ & $7.00^{\mathrm{a}}$ & $1.83^{b}$ & 2.17 \\
\hline 107.50 & $(M x+S z+P)$ & $8.33^{a}$ & $8.50^{\mathrm{abc}}$ & $4.67^{\mathrm{ab}}$ & $5.50^{\text {bcd }}$ & $3.67^{a}$ & 3.00 \\
\hline $\mathrm{SEM}^{3}$ & & 0.41 & 0.38 & 0.48 & 0.33 & 0.31 & 0.37 \\
\hline \multicolumn{8}{|c|}{ Main Effect Means ${ }^{4}$} \\
\hline \multicolumn{8}{|c|}{$\mathrm{ND}$} \\
\hline 100.00 & & 6.83 & 8.11 & 4.78 & 5.67 & $2.06^{b}$ & 2.44 \\
\hline 103.75 & & 6.94 & 8.50 & 4.78 & 5.78 & $2.17^{\mathrm{ab}}$ & 2.72 \\
\hline \multirow[t]{5}{*}{107.50} & & 7.44 & 8.44 & 4.83 & 6.11 & $2.61^{a}$ & 2.33 \\
\hline & FA & & & & & & \\
\hline & No & $6.61^{b}$ & 8.17 & 4.56 & 5.83 & $2.06^{b}$ & 2.33 \\
\hline & Maxi & $6.89^{b}$ & 8.39 & 4.83 & 5.83 & $2.06^{b}$ & 2.56 \\
\hline & $(M x+S z+P)$ & $7.72^{\mathrm{a}}$ & 8.50 & 5.00 & 5.89 & $2.72^{\mathrm{a}}$ & 2.61 \\
\hline SEM & & 0.24 & 0.22 & 0.27 & 0.19 & 0.18 & 0.22 \\
\hline \multicolumn{8}{|l|}{$p$-value } \\
\hline ND & & 0.169 & 0.411 & 0.986 & 0.247 & 0.080 & 0.427 \\
\hline FA & & 0.006 & 0.558 & 0.516 & 0.973 & 0.015 & 0.630 \\
\hline $\mathrm{ND} \times \mathrm{FA}$ & & 0.020 & 0.097 & 0.13 & 0.003 & 0.001 & 0.321 \\
\hline \multicolumn{8}{|c|}{ Orthogonal polynomials } \\
\hline \multicolumn{8}{|c|}{ ND } \\
\hline Linear & & 0.224 & 0.189 & 0.934 & 0.245 & 0.137 & 0.753 \\
\hline Quadratic & & 0.146 & 0.860 & 0.887 & 0.227 & 0.087 & 0.208 \\
\hline \multicolumn{8}{|l|}{ FA } \\
\hline Linear & & 0.022 & 0.310 & 0.288 & 0.907 & 0.137 & 0.348 \\
\hline Quadratic & & 0.018 & 0.724 & 0.669 & 0.839 & 0.012 & 0.856 \\
\hline
\end{tabular}

${ }^{a, b}$ Means in the same column with no common superscript for each effect are significantly different at $p \leq 0.05 .{ }^{1}$ Maxi-Gen ${ }^{\text {TM }}$ Plus at the rate of $0.5 \mathrm{~g} / \mathrm{kg}$ diet. ${ }^{2}$ (Maxi-Gen ${ }^{\mathrm{TM}}$ Plus, Superzyme ${ }^{\mathrm{TM}}-\mathrm{CS} 2 \mathrm{X}$, Bio-Phytase $5000 \mathrm{G}$ at the rate of $0.5,0.25$ and $0.1 \mathrm{~g} / \mathrm{kg}$ diet, respectively). ${ }^{3}$ Standard error of the mean. ${ }^{4}$ Mean represents 15 birds per pen, 18 pens per diet. 
Nabizadeh A, Golian A, Hassanabadi A, Zerehdaran S
Effects of Nutrient Density and exogenous enzymesin Starter Diet on Performance, Intestinal Microflora, Gut Morphology and Immune Response of Broiler Chickens response to the greater flow of nutrients. Amino acids, in addition to being components of proteins, regulate essential metabolic routes for maintenance, growth, and immunity. Also, they regulate gene expression and the synthesis of hormones and molecules of great biological importance such as glutathione, nitric acid, polyamines, and purine and pyrimidine nucleotides ( $\mathrm{Li}$ et al., 2007).

\section{Immune response}

The main effects of ND and FA in the starter diet and their interaction on total anti-SRBC, IgG, and IgM titers of broiler chickens at 35 and $42 \mathrm{~d}$ of age are shown in Table 5 . Feeding starter diet containing $107.5 \%$ ND and Maxi+Sz+P increased total anti-SRBC titers $(p=0.020)$ compared with those fed control or other diets, with the exception of those fed the diet containing 107.5\% ND and supplemented with MaxiGen at $35 \mathrm{~d}$ of age. The inclusion of Maxi-Gen alone in starter diet with $107.5 \%$ ND increased total anti-SRBC titers ( $p=0.097)$ and $\operatorname{lgG}(p=0.003)$ of chicks compared with those fed control and the other diets at $42 \mathrm{~d}$ of age. Panda et al. (2011) reported that diets containing $1.1 \%$ Lys compared to $1.4 \%$ significantly reduced humoral immune response in broiler chickens. The ND can affect the genes expression that responsible for immune response (Klasing \& Barnes, 1988) by altering the magnitude of antibody production and maturity of immune system (Latshaw, 1991). As antibodies are proteins, any essential amino acid deficiency especially during the growing period results in poor immune competence (Latshaw, 1991). Cowieson et al. (2017) based on gene expression patterns in jejunal tissue suggested that both dietary protein source and exogenous protease influence the expression of genes responsible for mucin secretion, amino acid transport and immune functionality in an age dependent manner.

\section{CONCLUSION}

It is concluded that higher nutrient density and the supplementation with the tested feed additive and its combination with a commercial enzyme blend and a phytase in starter diet can improve the overall growth performance of broiler chickens. The starter diet containing $107.5 \%$ ND and supplemented with MaxiGen or Maxi+Sz+P promoted better $(p<0.05)$ BWG and FCR compared with those fed the control diet or that with $103.75 \%$ ND at $42 \mathrm{~d}$ of age. The present study showed that ND and FA supplementation did not have any effect $(p>0.05)$ on the ileal microflora counts, but increased cecal beneficial bacteria counts $(p<0.05)$ of $10 \mathrm{~d}$ chicks. Duodenal and jejunal villus height and VCR increased $(p<0.05)$ when broiler chicks were fed starter diet containing $103.75 \%$ and $107.5 \%$ ND at 5 and $10 \mathrm{~d}$ of age. The supplementation with the additive combination increased $(p<0.05)$ duodenal and jejunal villus height at $5 \mathrm{~d}$ of age. Immune responses were enhanced with increasing ND and Maxi+Sz+P supplementation in the starter diet.

\section{ACKNOWLEDGMENTS}

The authors would like to thank the Vice President in Research and Technology, at the Ferdowsi University of Mashhad, for the funding of this study (Project \# 37844). Our appreciation is also extended to the Canadian bio-systems INC. Calgary, Alberta for their contribution of the feed additives.

\section{REFERENCES}

Adedokun SA, Parsons CM, Lilburn MS, Adeola O, Applegate TJ. Endogenous amino acid flow in broiler chicks is affected by the age of birds and method of estimation. Poultry Science 2007;86:2590-2597.

Bach Knudsen KE. Carbohydrate and lignin contents of plant materials used in animal feeding. Animal Feed Science and Technology 1997;67:319338.

Barekatain MR, Swick RA. Composition of more specialised pre-starter and starter diets for young broiler chickens:a review. Animal Production Science 2016;56:1239-1247.

Burnett GS. Studies of viscosity as the probable factor involved in the improvement of certain barleys for chickens by enzyme supplementation. British Poultry Science 1996;7:55-75.

Chen X, Zhang Q, Applegate TJ. Impact of dietary branched chain amino acids concentration on broiler chicks during aflatoxicosis. Poultry Science 2016;95(6):1281-1289.

Choct M, Hughes RJ, Wang J, Bedford MR, Morgan AJ, Annison G. Increased small intestinal fermentation is partly responsible for the anti-nutritive activity of non-starch polysaccharides in chickens. British Poultry Science 1996;37(3):609-621.

Cowieson AJ. Factors that affect the nutritional value of maize for broilers. Animal Feed Science and Technology 2005;77:345-353.

Cowieson AJ, Lu H, Ajuwon KM, Knap I, Adeola O. Interactive effects of dietary protein source and exogenous protease on growth performance, immune competence and jejunal health of broiler chickens. Animal Production Science 2017;57(2):252-261.

Everaert N, Swennen Q, Coustard SM, Willemsen H, Careghi C, Buyse J, et al. The effect of the protein level in a pre-starter diet on the post-hatch performance and activation of ribosomal protein 56 kinase in muscle of neonatal broilers. British Journal of Nutrition 2010;103:206-211.

Gottardo ET, Prokoski K, Horn D, Viott AD, Santos TC, Fernandes JIM. Regeneration of the intestinal mucosa in Eimeria and E. Coli challenged broilers supplemented with amino acids. Poultry Science 2016;95(5):1056-1065. 
Nabizadeh A, Golian A,

Hassanabadi A, Zerehdaran S
Effects of Nutrient Density and exogenous enzymesin

Starter Diet on Performance, Intestinal Microflora, Gut Morphology and Immune Response of Broiler

\section{Chickens}

Swennen Q, Everaert N, Debonne M, Verbaeys I, Careghi C, Tona K, et al. Effect of macronutrient ratio of the pre-starter diet on broiler performance and intermediary metabolism. Journal of Animal Physiology and Animal Nutrition 2010;94:375-384.

Van der Wielen PW, Biesterveld S, Notermans S, Hofstra H, Urlings BAP, van Knapen F. Role of volatile fatty acids in development of the cecal microflora in broiler chickens during growth. Journal of Applied \& Environmental Microbiology 2000;66:2536-2540.

Wang X, Peebles ED, Morgan TW, Harkess RL, Zhai W. Protein source and nutrient density in the diets of male broilers from 8 to $21 \mathrm{~d}$ of age: effects on small intestine morphology. Poultry Science 2015;94:61-67.

Willemsen H, Everaert N, Witters A, De Smit L, Debonne M, Verschuere F, et al. Critical assessment of chick quality measurements as an indicator of post hatch performance. Poultry Science 2008;87:2358-2366.

Yang Y, lji PA, Kocher A, Mikkelsen LL, Choct M. Effects of Mannan oligosaccharide on growth performance, the development of gut microflora, and gut function of broiler chickens raised on new litter. Journal of Applied Poultry Research 2007;16:280-288.

Zhai W, Peebles ED, Zumwalt CD, Mejia L, Corzo A. Effects of dietary amino acid density regimens on growth performance and meat yield of Cobb $\times$ Cobb 700 broilers. Journal of Applied Poultry Research 2013;22:447460 .

Zhai W, Peebles ED, Mejia L, Zumwalt CD, Corzo A. Effects of dietary amino acid density and metabolizable energy level on the growth and meat yield of summer reared broilers. Journal of Applied Poultry Research 2014;23:501-515

Zhu HL, Hu LL, Hou YQ, Zhang J, Ding BY. The effects of enzyme supplementation on performance and digestive parameters of broilers fed corn-soybean diets. Poultry Science 2014;93:1704-1712.

Zou XT. Qiao XJ, Xu ZR. Effect of $\beta$-mannanase (hemicell) on growth performance and immunity of broilers. Poultry Science 2006;85:21762179. 
